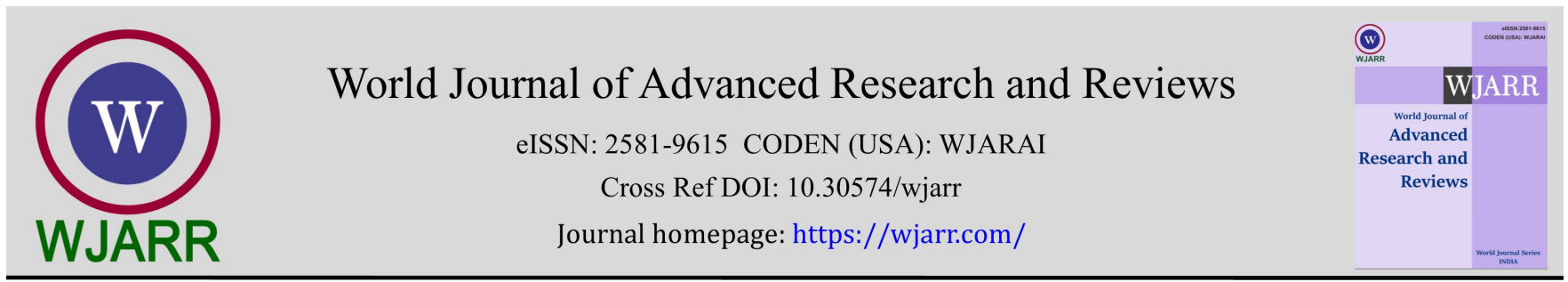

(REVIEW ARTICLE)

\title{
Nano-0xy: Diabetic ulcer treatment using oxygen nanoparticles concept as innovation in reducing amputation rates and antibiotics usage
}

\author{
Shofiuddin Al Mufid 1, Naufal Achmad Tsany Daffa 1, Dedy Firmansyah 1, Octaviana Galuh Pratiwi 1, Innas \\ Safira Putri ${ }^{1}$ and Reny I'tishom ${ }^{2, *}$
}

${ }^{1}$ Medical Study Program, Faculty of Medicine, Universitas Airlangga, Surabaya.

2 Department of Biomedical Science, Faculty of Medicine, Unviersitas Airlangga, Surabaya.

World Journal of Advanced Research and Reviews, 2022, 13(01), 309-316

Publication history: Received on 07 December 2021; revised on 09 January 2022; accepted on 11 January 2022

Article DOI: https://doi.org/10.30574/wjarr.2022.13.1.0031

\begin{abstract}
Diabetes mellitus is a metabolic disease characterized by chronic hyperglycemia caused by defects in insulin secretion, insulin reactions, or both. More than one third of diabetic patients have complications in the form of diabetic ulcers, and half are infected, and 15\% of these infections require limb amputation. High cost expenditure and risks of microbial resistance to antibiotics also adds the complexity of the problem.

The purpose of this literature review is to offer Nano-Oxy, using oxygen in nanoparticle size, as an alternative diabetic ulcer treatment. Literature searching was conducted through online search method. Oxygen therapy has been widely used to treat diabetic ulcers, including hyperbaric oxygen therapy (HOT) and topical oxygen therapy (TOT). Both of them have good results on diabetic ulcer therapy. Oxygen can act as an antimicrobial agent through the activation mechanism of neutrophils and macrophages which play a role in phagocytosis process and ROS regeneration. Nano-Oxy has advantages than the previous therapy, such as it does not cause barotrauma, oxygen poisoning, and low risk of burning.

The mechanism of how Nano-Oxy works is similar with the Micro-nanobubbles (MNBs) concept. The negatively charged surface of MNBs can prevent them from aggregating, attracts particles, and help remove debris. MNBs also generate free radicals while shrinking in water, which contribute to its antibacterial effect. In addition, Nano-oxygen technology can be applied externally, but still have effect on the intended target cells. Therefore, Nano-oxygen can be used as a diabetic ulcer therapy to replace the role of antibiotics.
\end{abstract}

Keywords: Diabetic Ulcer; Bacteria Resistant; Diabetes Mellitus; Nano Oxygen; Oxygen Therapy

\section{Introduction}

Diabetes mellitus is one of metabolic diseases characterized by chronic hyperglycemia caused by defects in insulin secretion, insulin reactions, or both [1]. The number of people with diabetes is expected to increase rapidly from 425 million in 2017 to a predicted value of 600 million in 2030. More than a third of people with diabetes have complications in the form of diabetic ulcers during their lifetime, half are infected, and $15 \%$ of these infections require limb amputation to prevent the development of infection [2]. The longer a person has diabetes mellitus, the greater the chance of suffering from chronic hyperglycemia which will eventually cause complications in the form of retinopathy, nephropathy, $\mathrm{CHD}$, and diabetic ulcers [3].

\footnotetext{
* Corresponding author: Reny I'tishom

Department of Biomedical Science, Faculty of Medicine, Unviersitas Airlangga, Surabaya.

Copyright $(2022$ Author(s) retain the copyright of this article. This article is published under the terms of the Creative Commons Attribution Liscense 4.0.
} 
The microbiota in diabetic ulcers is affected by several factors, such as demographic characteristics, personal hygiene, geographic origin of the patient, severity, glycemic control, and current or previous antibiotic treatment [4]. Gardner et al. found that poor glycemic control was associated with higher Staphylococcus sp. and Streptococcus sp. counts [5]. In the same comparative study, they showed that ulcer depth was positively correlated with abundance of anaerobic bacteria, and negatively correlated with abundance of Staphylococcus sp.. In addition, ulcer duration was positively correlated with bacterial diversity, species richness, and relative abundance of Proteobacteria sp., but negatively correlated with relative abundance of Staphylococcus sp.. Since a healthy skin microbiota tends to be limited in water and nutrients, hydration and nutrient availability may have a marked effect on wound microbial composition [6].

While antibiotic treatment for diabetic infections is initially prescribed empirically, accurate bacterial identification of diabetic infections can improve therapeutic approaches. Selection of the most effective antibiotics is an important step in reducing the treatment period, preventing the expansion of resistant bacterial strains, and limiting healthcare costs [7]. Methicillin-Resistant Staphylococcus aureus (MRSA) is a common bacterial pathogen in diabetic infections and is difficult to treat.

Because of the reasons already mentioned, it is necessary to innovate the treatment of diabetic ulcers by minimizing the use of antibiotics. The purpose of this literature review is to review the potential of oxygen, its form, and the effective administration of oxygen in diabetic ulcers.

\section{Material and methods}

This Literature Review was written as the result of various related literature studies and supported by discussion analysis. The literature searching was conducted through an online search method using various databases, such as Pubmed, Sciencedirect, NIH NCBI, Google Scholar, and Research Gate. Besides that, the literature searching is also done through offline search method. The keywords that is used are: Diabetic Ulcer, Bacteria Resistant, Diabetes Mellitus, Nano Oxygen, and Oxygen Therapy. The inclusion criteria for included studies are publications in English or Indonesian language in the last 10 years. We found 39 literatures with various study design, including systematic reviews, metaanalysis, randomized controlled trials, case-control studies, and literature in other forms such as dissertations. The level of evidence is determined based on the classification issued by the Oxford Centre for Evidence-based Medicine Level of Evidence [8].

\section{Results and discussion}

\subsection{Oxygen Therapy againts Diabetic Ulcer}

Oxygen has been widely used as a therapy for diabetic ulcers, because it has a role in the formation of collagen type 1 [9]. There are several therapeutic methods that are becoming commonly used, namely hyperbaric oxygen therapy and topical oxygen therapy.

\subsubsection{Hyperbaric Oxygen Therapy (HOT)}

HOT is a treatment procedure where the patient is exposed to $100 \%$ oxygen for a certain period of time and certain pressure, higher than atmospheric pressure. There are 2 main mechanisms in HOT which are hyperoxygenation and decrease in bubble size. Oxygen plays an important role in wound healing. This therapy is carried out in a monoplace or multiple room. The $\mathrm{O}_{2}$ pressure for HOT must be at least 1.4 atmospheres absolute or higher. In the monoplace chamber, a patient inhales $100 \% \mathrm{O}_{2}$ indirectly by a hood, mask, or endotracheal tube [10]. This therapy is generally given as primary or alternative therapy in cases of inflammation, carbon monoxide (CO) poisoning, chronic wounds, ischemia, and infection [11]. The application of HOT to diabetic ulcers has been reported to have greatly increased the frequency of diabetic ulcer healing and reduced the need for amputation and debridement requiring surgical equipment. Liu et al. conducted a meta-analysis of 13 controlled trials including the Randomized Controlled Trial, a non-randomized controlled trial and a case-control study, consisting of a total of 624 patients with ischemic and non-ischemic wounds, and reported improved healing rates significantly (RR 2.33,95\% CI:1.51 to 3.60) and decreased the rate of major amputations (RR 0.29, 95\% CI: 0.91 to 0.44 ) [12]. Results from observational studies have also been summarized by O'Reilly et al [13] In a combined analysis of four comparative observational studies consisting of 191 patients, HOT significantly reduced the risk of major amputation (RR $0.39,95 \% \mathrm{CI}: 0.21-0.73$ ) [12]. 


\begin{tabular}{|c|c|c|c|c|c|c|c|c|}
\hline Study or Subgroup & \multicolumn{2}{|c|}{ НВОТ } & \multicolumn{2}{|c|}{ Control } & Weight & $\begin{array}{c}\text { Risk Ratio } \\
\text { M-H, Fixed, } 95 \% \mathrm{Cl}\end{array}$ & \multicolumn{2}{|c|}{$\begin{array}{c}\text { Risk Ratio } \\
\text { M-H, Fixed, } 95 \% \mathrm{Cl}\end{array}$} \\
\hline Baroni 1987 & 2 & 18 & 4 & 10 & $17.6 \%$ & $0.28[0.06,1.26]$ & & \\
\hline Faglia 1998 & 7 & 51 & 20 & 64 & $60.9 \%$ & $0.44[0.20,0.96]$ & & \\
\hline Kalani 2002 & 2 & 17 & 7 & 21 & $21.5 \%$ & $0.35[0.08,1.48]$ & & \\
\hline Zamboni 1997 & 0 & 5 & 0 & 5 & & Not estimable & & \\
\hline Total $(95 \% \mathrm{Cl})$ & & 91 & & 100 & $100.0 \%$ & $0.39[0.21,0.73]$ & & \\
\hline Total events & 11 & & 31 & & & & & \\
\hline $\begin{array}{l}\text { Heterogeneity: } \mathrm{Chi}^{2}= \\
\text { Test for overall effect }\end{array}$ & $\begin{array}{l}0.30, \mathrm{df}= \\
Z=2.95\end{array}$ & $\begin{array}{l}2(P= \\
P=0.0\end{array}$ & $\begin{array}{l}0.86) ; 1^{2}= \\
03)\end{array}$ & $=0 \%$ & & & $\begin{array}{ll}0.01 & 0.1 \\
\text { Favours HBOT }\end{array}$ & $\begin{array}{c}10 \quad 100 \\
\text { Favours Control }\end{array}$ \\
\hline
\end{tabular}

Figure 1 Meta-analysis of observational studies indicated a significant difference mayor amputations between two groups [13]

Behind the advantages of HOT, there are still some side effects. Sending $\mathrm{O}_{2}$ to the lungs causes an increase in oxygen pressure in the circulation and tissues. Adverse effects arising from barotrauma and oxygen poisoning also have a negative impact on their wide application, along with practical limitations such as accessibility and cost of treatment [14].

\subsubsection{Topical Oxygen Therapy (TOT)}

With a growing understanding of the limitations of HOT, various TOT methodologies have been developed to provide more effective external oxygen delivery, bypass circulation problems and improve accessibility [15]. TOT allows for more effective therapy because it has a portable device. The TOT device produces $\mathrm{O}_{2}$ from water molecules in the atmosphere at a concentration of about $98 \%$ and a rate of about $13 \mathrm{ml}$ per hour. The concentration of oxygen produced under the dressing varies depending on the wound area, the permeability of the dressing, and the degree of oxygen leakage from around the edges of the dressing. An oxygen distribution system is provided at the wound site with conventional dressings and generators that can be placed in various places, including a trouser pocket [16].

In the study conducted by Kaufman et al., the best results using TOT were seen after day 25, with complete wound closure in $57 \%$ of arterial and diabetic ulcers and in $47 \%$ of venous ulcers previously considered intractable [17]. The greatest reduction in wound area was in the venous ulcer $(\mathrm{p}<0.001), 83 \%$ over the course of the study, with an average closing rate of $9.5 \%$ per week. Arterial and diabetic ulcers had an overall wound reduction of $74 \%(p<0.001)$.

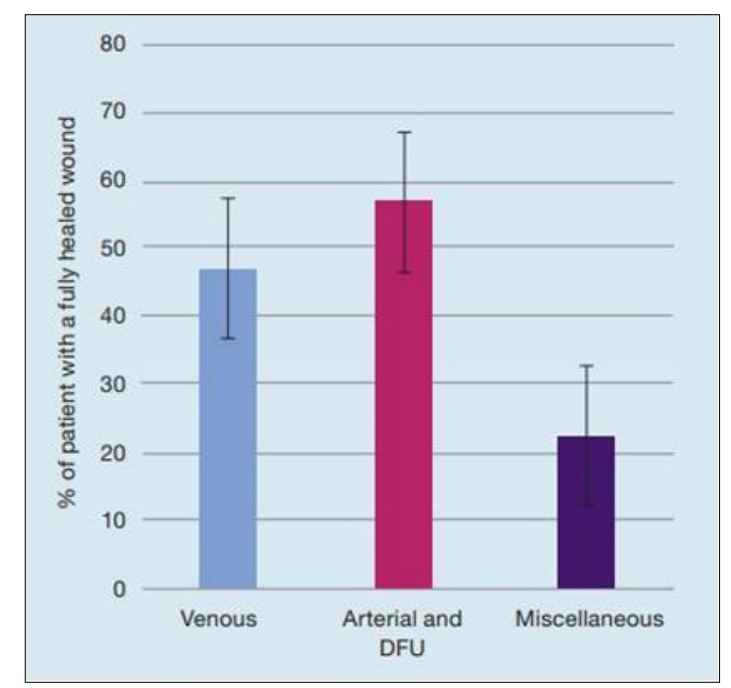

Figure 2 Total Wound Closure Rate. Total Wound Closure Rates for Various Pathologies in Patients Completing 25 Days TOT [17] 


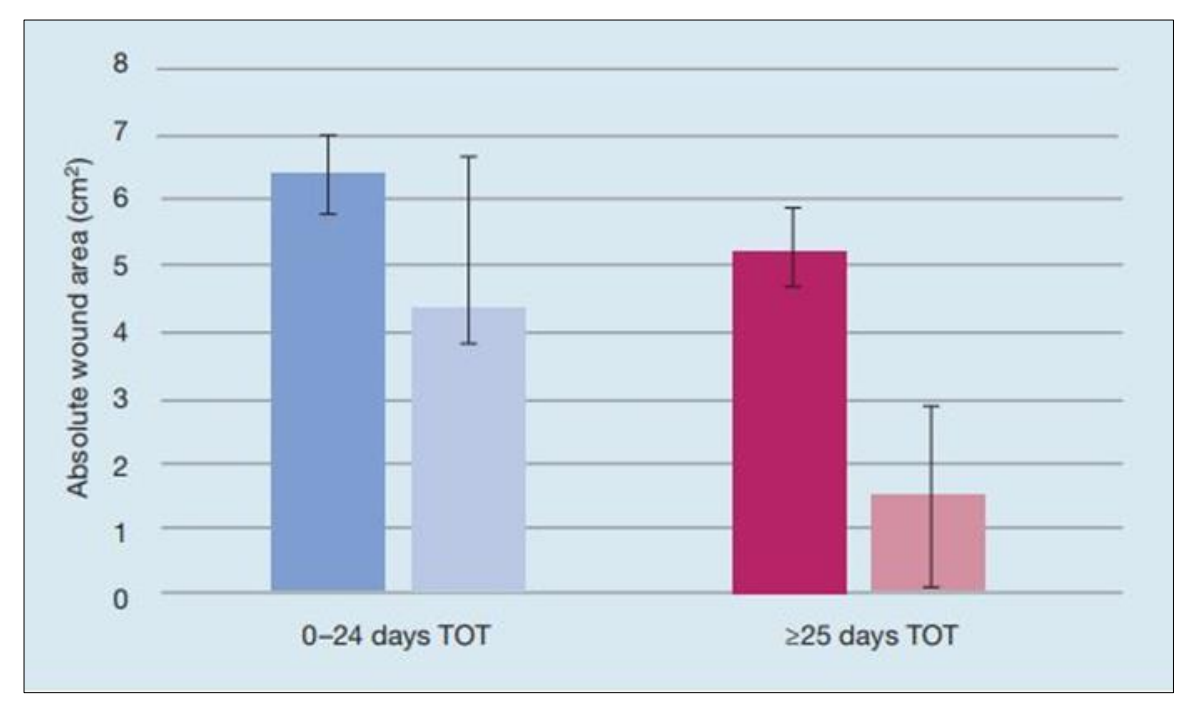

Figure 3 Intergroup Mean Wound Area Reduction. Reduction of Wound Area Size between Begin and End of Treatment for Patients Receiving TOT for More Than 25 Days [17]

The advantage of topical oxygen is its ability to act on many different facets of wound healing, making it more likely to close chronic wounds than therapy directed at only one or two pathophysiological processes [17]. On the other hand, TOT has a limited ability to penetrate the skin [18].

\subsection{Oxygen as antimicrobial agent that can replace the role of antibiotics}

Due to the hyperoxic conditions caused by the use of oxygen as therapy, several physiological and biochemical changes occur that contribute to increased antimicrobial activity and apoptosis [19].

Oxygen is known to function to stimulate the activity of neutrophils and macrophages [20]. Phagocytosis is basically a cell cleaning crew. Neutrophils and macrophages clear wound-invading bacteria and associated materials through the generation of Reactive Oxygen Species (ROS) requiring large amounts of energy and oxygen, leading to a significant increase in local cellular oxygen consumption [21]. After phagocytosis occurs, a complex reaction involving superoxide $\left(\mathrm{O}_{2-}\right)$, peroxide $\left(\mathrm{O}_{2-2}\right)$, hydrogen peroxide $\left(\mathrm{H}_{2} \mathrm{O}_{2}\right)$, hydroxyl radicals $(\mathrm{OH} \%)$ and hydroxyl ions $(\mathrm{OH}-)$ continues as alternative metabolites of several biological pathways. cells and antimicrobial peptides are used to kill and dissolve bacteria $[21,22,23]$.

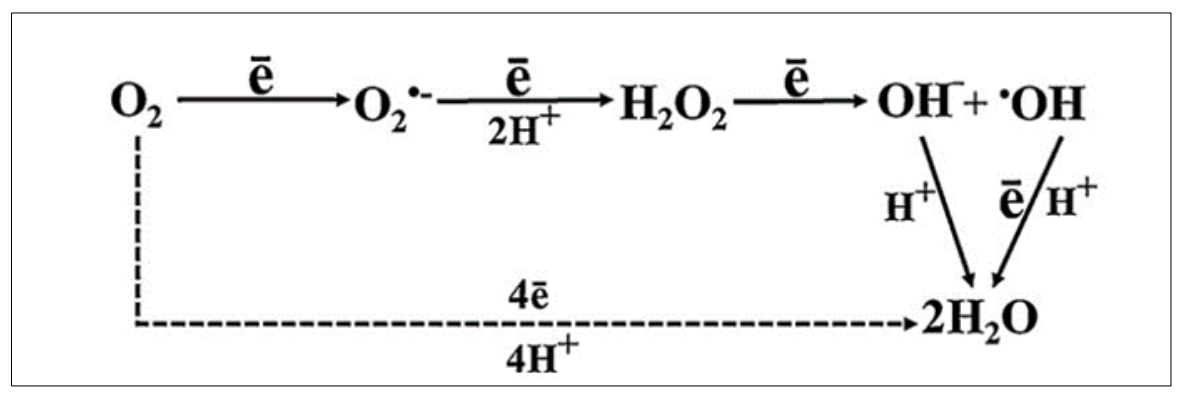

Figure 4 ROS formation: successive addition of two 02 is associated with ROS formation [24]

An oxygen tension of $30-40 \mathrm{mmHgPO}_{2}$ is required for fibroblast collagen synthesis. For all of the mentioned mechanisms, substantial oxygen is required at the wound site to allow bacterial reduction or healing activity. Therefore, without an adequate amount of oxygen, bacterial clearance will not be effective [25].

\subsection{Nano-0xygen that can be applied from outside the body to target cells}

Oxygen plays a role in forming type 1 collagen in wound healing [26]. Oxygen is an important nutrient carried by the body's red blood cells. In addition to forming type 1 collagen, $\mathrm{O}_{2}$ is needed in the oxygenation process for various important reactions in wound healing. In people with diabetes mellitus with vascular disorders, the amount of oxygen in the blood is likely to be blocked, the condition is exacerbated by the presence of high sugar levels in the body. The 
author uses oxygen as the main ingredient based on the theory of TOH and TOT in healing diabetic ulcers. However, oxygen is applied in a different way to minimize the drawbacks of TOH and TOT therapy.

The oxygen that will be applied is liquid oxygen which is processed into nanoparticles. Oxygen (liquid) in the form of nano will later be applied externally to the local area of diabetic ulcers. On a small scale, nano spray can be a medium for applying oxygen nanoparticles to ulcers. Nano spray is a tool that breaks up particles into nano size to then be injected in the form of nano liquid which is almost invisible to the eye. Nanoparticles are being developed rapidly in Indonesia, and are even commonly applied in several countries. The ability of nanoparticles to increase the bioavailability of drugs with low solubility in the systemic circulation has been widely demonstrated [27]. Because of these various capabilities, nanoparticles are often the choice in various other technologies, including the medical field.

Therefore, the authors apply nano-particles in the hope that oxygen can more easily penetrate local areas of the skin layer for healing diabetic ulcers. The way the author describes this work is in line with the system of Micro-nanobubbles (MNBs). MNBs are gas bubbles. The size of these mini gas bubbles varies in each literature, but the authors classify the diameters of microbubbles between $<100 \mathrm{M}$ and $1 \mathrm{M}$ while nanobubbles are $<1 \mathrm{M}$ [28]. MNB technology has been widely used in various fields for various purposes such as wastewater treatment, biofuel production, and agriculture [29].

The properties that make MNBs unique are their stability in water for a relatively long time. It will slowly rising and shrinking to the surface and finally collapse [28]. Unlike microbubbles, nanobubbles are difficult to observe through an optical microscope. Techniques such as laser backscatter or dynamic laser should be used to observe the size of the nanobubbles. Nanobubbles are durable in liquids and can be present in bulk or on submerged hydrophobic surfaces [29]. Because the internal pressure of the MNB is higher than its surroundings, the MNB promotes the solubility of its internal gases, often oxygen into a liquid where it is produced [28]. When MNBs are produced in water using oxygen or air as the gas in their cores, the negatively charged surface of MNBs is not only prevents them from joining, which would cause them to lose strength, but also attracts particles and helps remove debris [28]. In addition, MNBs generate free radicals upon shrinkage, which may contribute to their antibacterial effect [30].

Several studies have been conducted by several researchers regarding the experimental application of these MNBs on experimental animals in the form of mice. The results of these experiments showed a significant increase in the application of oxygen MNBs to hypoxic skin [31]. At the cellular level, nanobubbles are found not only neutralized the unbalanced hypoxic dysregulation of MMP/TMP in human keratinocytes, but also reduced HIF-1-al signaling, both of which are important in wound healing. In addition, by means of fluorescent labeling, the researchers demonstrated that the nanobubbles were internalized by cells, including keratinocytes, with a cytoplasmic diffusion distribution [32,33]. In addition, studies looking at the potential detrimental effects of MNBs did not find any cellular toxicity associated with their application $[31,32,33]$.

\subsection{Nano-0xygen as a diabetic ulcer therapy replaces the role of antibiotics}

Antibiotics have been shown to reduce infections caused by microbes and are considered as a major advance in modern medicine [34]. Unfortunately, the efficacy of antibiotics declines over time as a lot of pathogens develop resistance. The phenomenon of resistance has been found in almost all classes of antibiotics as a result of mutations in microorganisms. To deal with this global antimicrobial resistance challenge, reduction of unnecessary use of antibiotics and controlled monitoring of infection management can reduce the rate of pathogen resistance. Besides that, alternative treatments are also urgently needed $[35,36]$.

One of the diseases that are prone to infection is Diabetic Ulcers or also known as Diabetic Foot Infections. Diabetic ulcers are a complication in individuals who have diabetes with an incidence of $25 \%$. Infections are common (40\%$80 \%$ ) and the complex complications of diabetic ulcers can increase the risk of morbidity and mortality [37, 38]. Diabetic foot infections are generally caused by polymicrobial infections with obligate and facultative anaerobic pathogens can be isolated from this infection $[37,38]$.

Therefore, the authors suggested using nano-oxygen as a substitute for antibiotics in preventing infection in diabetic ulcers. The principle that the author uses is not much different from the method of applying HOT and TOT which uses pure $\mathrm{O}_{2}$ to increase the supply of $\mathrm{O}_{2}$ so that it can help accelerate the healing of diabetic ulcers. There is sufficient evidence to show that HOT and TOT offer a valuable advantage, either alone or as adjunctive treatment, for patients with infectious disease. It has been found that HOT and TOT strongly stimulate the level of $\mathrm{O}_{2}$ concentration in the blood, which is usually very slow but should provide the primary requirement for normal tissues [39]. This effect is considered important for the healing of inflammatory and microcirculatory disorders in ischemic states. 


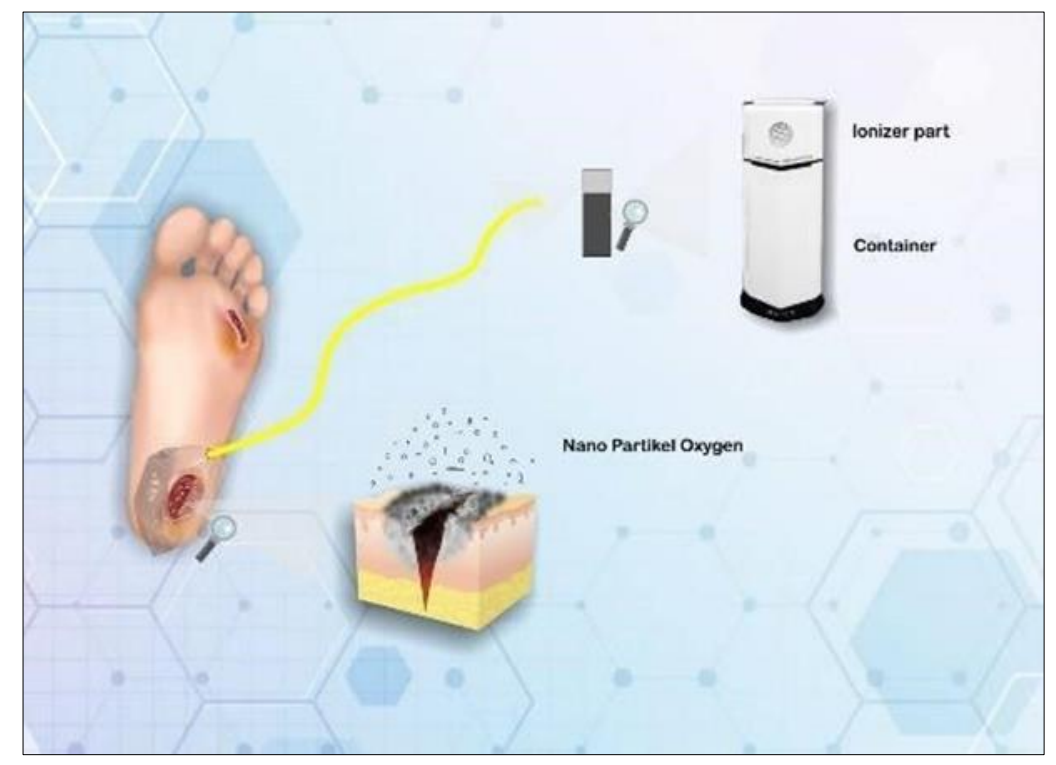

Figure 5 Nano-Oxy: model and usage

The application of Nano-Oxy using Nano Spray is directly applied to diabetic ulcer wounds. Nano-Oxygen will enter through the pores of the skin layer and will reach the blood vessels around the wound. This Nano Spray will be used with a plastic mask that will adjust to the shape of the wound and glued with adhesive with the aim that the NanoOxygen that is sprayed is focused only on specific intended wound. The Nano-Spray will be designed in such a way that the Nano-Oxygen will be sprayed automatically for a certain period of time so that the patient does not need to press the spray button repeatedly.

Nano-Oxy is the answer to the shortcomings of previous oxygen therapy. When HOT has side effects of barotrauma and oxygen poisoning due to its application throughout the body, as well as practical limitations such as accessibility and cost of treatment [6]. Nano-Oxy does not have these side effects, because of the principle of only sprays oxygen externally on the injured area, similar to the TOT principle. Therefore, in using Nano-Oxy, there is no need for professionals, can easily be done at home, and saves expenses. Besides that, TOT's limited ability to penetrate the skin can be enhanced by the use of Nano-Oxy which can break down oxygen particles so that they are nano-sized and can penetrate cells.

\section{Conclusion}

Nano-Oxygen can be used as an effective alternative therapy for diabetic ulcers treatment. Nano-Oxygen utilizes oxygen as an antimicrobial agent that are converted into nano-sized particles and using nano spray as the modifier. NanoOxygen that is applied externally to the local area of diabetic ulcers can penetrate into the skin and reach target cells. This tool has advantages compared to previous therapies, such as it does not cause barotrauma, oxygen poisoning, and low risk of burning. In addition, Nano-Oxygen can reduce the cost of treatment for diabetic ulcer patients. We hoped that the innovation of Nano-Oxygen can provide great benefits for diabetic ulcer sufferers so that it can increase the prosperity of the Indonesian people. For the future perspective, further experimental and clinical trials are needed to obtain real scientific evidence.

\section{Compliance with ethical standards}

\section{Acknowledgments}

We would like to thank all the authors and our mentor for their contribution to paper writings.

\section{Disclosure of conflict of interest}

The authors declare that there is no conflict of interest that would affect the findings of this study. 


\section{References}

[1] Kharroubi AT, Darwish HM. Diabetes mellitus: The epidemic of the century. World J Diabetes. 2015; 6(6): 850867.

[2] Commons, RJ, Raby E, Athan E, et al. managing diabetic foot infections: A survey of Australasian infectious diseases clinicianS. J. Foot Ankle Res. 2018; 11: 13.

[3] Roza RL, Afriant R, Edward Z. Faktor risiko terjadinya ulkus diabetik pada pasien diabetes mellitus yang dirawat jalan dan inap di RSUP Dr. M. Djamil dan RSI Ibnu Sina Padang. Jurnal Kesehatan Andalas. 2015; 4(1).

[4] Gardner SE, Hillis SL, Heilmann K, Segre JA, Grice EA. The neuropathic diabetic foot ulcer microbiome is associated with clinical factors. Diabetes. 2013; 62: 923-930.

[5] Oates A, Bowling FL, Boulton AJM, McBain AJ. Molecular and culture-based assessment of the microbial diversity of diabetic chronic foot wounds and contralateral skin sites. J Clin Microbiol. 2012; 50: 2263-2271.

[6] Abbas, M.; Uçkay, I.; Lipsky, B.A. In diabetic foot infections antibiotics are to treat infection, not to heal wounds. Expert Opin. Pharmacother. 2015; 16: 821-832.

[7] Irawan H dan Kartika. TOH sebagai Terapi Adjuvan Kaki Diabetik. Analisis. 2016; 43(10): $782-785$.

[8] Jeremy H, Iain C, Paul G, et al. The Oxford 2011 Levels of Evidence. Oxford Centre for Evidence-Based Medicine. 2011.

[9] Wounds International. International best practice guidelines: Wound management in diabetic foot ulcers [internet]. London: Wounds International. 2018.

[10] Buckley Na, Juurlink DN, Isbister G, et al. Hyperbaric oxygen for carbon monoxide poisoning. Cochrane Database Syst Rev. 2011; 4: 20-41.

[11] Memar MY, Ghostalou R, Samiei M, Adibkia K. Antimicrobial use of Reactive oxygen therapy: current insight. Infect Drug Resist. 2018; 11: 567.

[12] Liu R, Li L, Yang M, Boden G, Yang G. Systematic review of the effectiveness of hyperbaric oxygenation therapy in the management of chronic diabetic foot ulcers. Mayo Clin Proc. 2013; 88: 166-175.

[13] O'Relly D, Pasricha A, Campbell K, Burke N, Assasi N, Bowen JM, et al. Hyperbaric oxygen therapy for diabetic ullcers: systematic review and meta- analysis. Int J Technol Asses Health Care. 2013; 29: 269.

[14] Thom SR. Hyperbaric oxygen: its mechanisms and efficacy. Plast Reconstr Surg. 2011; 127(1): 131-141.

[15] Sayadi LR, Banyard DA, Ziegler ME, et al. Topical oxygen therapy \& micro/nanobubbles: a ew modality for tissue oxygen delivery. Int Wound J. 2018; 15: 363-374.

[16] Hayes PD, Alzuhir N, Curran G, et al. Topical oxygen therapy promotes the healing if chronic diabetic foot ulcers: a pilot study. J Wound Care. 2017; 26(11): 654-660.

[17] Kaufman H, Gurevich M, Tamir E, et al. Topical oxygen therapy stimulates healing in difficult, chronic wounds: a tertiary centre experience. J Wound Care. 2018; 27: 7.

[18] Maeda Y, Hosokawa S, Baba Y, Tomiyama A, Ito Y. Generation mechanism of micro-bubbles in a pressurized dissolution method. Exp Thermal Fluid Sci. 2015; 60: 201-207.

[19] Almzaiel AJ, Billington R, Smerdon G, et al. Effect of hyperbaric oxygen treatment on antimicrobial function and apoptosis of differentiated HL-60 (neutrophil-like) cells. Life Sci. 2013; 93: 125-131.

[20] Chandra PK, Ross CL, Smith LC et al. Peroxide-based oxygen generating topical wound dressing for enhancing healing of dermal wounds. Wound Repair Regen. 2015; 23(6): 830-841.

[21] Dunnill C, Patton T, Brennan J et al. Reactive oxygen species (ROS) and wound healing: the functional role of ROS and emerging ROS-modulating technologies for augmentation of the healing process. Int Wound J. 2017; 14(1): 89-96.

[22] Slauch, J. M. How does the oxidative burst of macrophages kill bacteria? Still an open question. Molecular Microbiology. 2011; 80: 580-583.

[23] Dryden M. Reactive oxygen therapy: a novel therapy in soft tissue infection. Curr. Opn. Infect. Dis. 2017; 30(2): 143-149. 
[24] Memar MY, Yekani M, Alizadeh N, et al. Hyperbaric oxygen therapy: Antimicrobial mechanisms and clinical application for infections. Biomedicine \& Pharmacotherapy. 2019; 109: 440-447.

[25] Klopfer MJ. Micro and Nanobubbles for Wound Healing Applications [Dissertation]. Oakland: University of California; 2015.

[26] Rizka A, Vicky SB, Dyah F. Kepadatan Kolagen Tipe 1 pada luka operasi Tikus Wistar yang Mengalami Anemia Karena Pendarahan Akut. Repository Universitas Airlangga. 2013; 2(1): 1-12.

[27] Bhatia A, Shard P, Chopra D, and Mishra T. Chitosan nanoparticles as carrier of immunorestoratory plant extract: synthesis, characterization and immunorestoratory efficacy. International J Drug Deliv. 2011; 3: 381-385.

[28] Matsuki N, Ichiba S, Ishikawa T, et al. Blood oxygenation using microbubble suspensions. Eur Biophys J. 2012; 41(6): 571-578.

[29] Seddon JR., Lohse D, Ducker WA, Craig VSA. A deliberation on nanobubbles at surfaces and in bulk. Chem Phys Chem. 2012; 13: 2179-2187.

[30] Matsuki N, Ishikawa T, Ichiba S, Shiba N, Ujike Y, Yamaguchi T. Oxygen supersaturated fluid using fine micro/nanobubbles. Int J Nanomedicine. 2014; 9: 4495-4505.

[31] Magnetto C, Prato M, Khadjavi A, et al. Ultrasound-activated decafluoropentane- cored and chitosan-shelled nanodroplets for oxygen delivery to hypoxic cutaneous tissues. RSC Adv. 2014; 4(72): 38433-38441.

[32] Khadjavi A, Magnetto C, Panariti A, et al. Chitosan-shelled oxygen-loaded nanodroplets abrogate hypoxia dysregulation of human keratinocyte gelatinases and inhibitors: new insights for chronic wound healing. Toxicol Appl Pharmacol. 2015; 286(3): 198-206.

[33] Basilico N, Magnetto C, D'Alessandro S, et al. Dextran-shelled oxygen-loaded nanodroplets reestablish a normoxia-like pro-angiogenic phenotype and behavior in hypoxic human dermal microvascular endothelium. Toxicol Appl Pharmacol. 2015; 288(3): 330-338.

[34] Piddock LJ. The crisis of no new antibiotics — what is the way forward? Lancet Infect Dis. 2012; 12(3):249-253.

[35] Memar MY, Raei P, Alizadeh N, et al. Carvacrol and thymol: strong antimicrobial agents against resistant isolates. Rev Med Microbiol. 2017; 28(2): 63-68.

[36] Dryden M, Cooke J, Salib R, et al. Reactive oxygen therapy: antimicrobial and immunological mechanisms, safety and clinical applications. J Glob Antimicrob Resist. 2017; 8: 194-198.

[37] Dryden M, Akhi MT, Ghotaslou R. Bacterial etiology and antibiotic susceptibility pattern of diabetic foot infection in Tabriz, Iran. GMS Hyg Infect Control. 2015; 10: 1-6.

[38] Akhi M.T, Ghotaslou R, Memar MY, et al. Frequency of MRSA in diabetic foot infections. Int J Diabetes Dev. 2017; 37(1): 58-62.

[39] Van Meter KW. The effect to hyperbaric oxygen on severe anemia. Undersea Hyperb Med. 2012; 39 (5): 937. 